\title{
Exploring the role of glucose-6-phosphate dehydrogenase in cancer (Review)
}

\author{
RUI LI ${ }^{1,2}$, WANG WANG ${ }^{2}$, YE YANG ${ }^{2}$ and CHUNYAN GU ${ }^{1,2}$ \\ ${ }^{1}$ Large Data Center, The Third Affiliated Hospital of Nanjing University of Chinese Medicine, Nanjing, Jiangsu 210001; \\ ${ }^{2}$ School of Medicine and Holistic Integrative Medicine, Nanjing University of Chinese Medicine, \\ Nanjing, Jiangsu 210023, P.R. China
}

Received April 2, 2020; Accepted August 26, 2020

DOI: $10.3892 /$ or.2020.7803

\begin{abstract}
Glucose-6-phosphate dehydrogenase (G6PD) is a cytoplasmic enzyme found in human erythrocytes that provides reduced NADPH for cell metabolism. Glutathione produced by the G6PD pathway can reduce the degree of harm caused by reactive oxygen species such as oxygen-containing free radicals, peroxides and lipid peroxides. Investigation of G6PD has long focused on hemolysis, jaundice and other diseases caused by defects in its function. However, increased mRNA expression levels of G6PD are predictive of adverse clinical outcomes in cancer patients, including increased drug resistance, migration or proliferation of tumor cells. Mutations in the G6PD gene affect protein expression and activity, and alters the balance of redox states, leading to disease. However, the association between G6PD and tumors is incompletely understood. The aim of the present review was to summarize the current body of knowledge on the role of G6PD in tumor progression and the possible regulatory mechanisms involved. It is hypothesized that G6PD will prove to be of value as a target of cancer treatment in the near future.
\end{abstract}

\section{Contents}

1. Introduction

2. Biological function of G6PD in normal cells

3. Abnormal status and function of G6PD in cancer cells

4. Role of G6PD in cancer and the related networks

5. G6PD and cancer treatment

6. Conclusion

Correspondence to: Professor Chunyan Gu or Professor Ye Yang, School of Medicine and Holistic Integrative Medicine, Nanjing University of Chinese Medicine, B8-212, 138 Xianlin Road, Nanjing, Jiangsu 210023, P.R. China

E-mail: guchunyan@njucm.edu.cn

E-mail: yangye876@sina.com

Key words: G6PD, pentose phosphate pathway, NADPH, cancer, drug resistance

\section{Introduction}

Glucose-6-phosphate dehydrogenase (G6PD) is conventionally considered as the first and rate-limiting enzyme of the pentose phosphate pathway (PPP), is present in the cytoplasm of red blood cells and protects cells against oxidative damage (1). PPP produces large quantities of NADPH and ribose 5-phosphate for various cellular synthetic functions, such as the synthesis of aliphatic acid and sterols. In addition, this pathway ensures glutathione $(\mathrm{GSH})$ reduction, which enhances antioxidant defense and promotes cell proliferation (2). Individuals with clinical G6PD deficiency are prone to neonatal jaundice, infection or drug hemolysis, chronic non-spherical red blood cell hemolytic anemia and abnormal lipid metabolism (3). Furthermore, mutations in G6PD have been previously demonstrated to be the primary cause of certain diseases, such as chronic hemolytic anemia (4).

It has been shown that the expression of G6PD in tumor cells is higher compared with that in normal cells, and its expression is associated with the overall survival of tumor patients $(2,5)$. Numerous studies have also demonstrated increased G6PD activity in several types of cancer, including bladder cancer, carcinoma of the endometrium, prostate cancer, kidney cancer, stomach cancer, cholangiocarcinoma, colon adenocarcinoma, lung cancer, cervical cancer, carcinoma of the ovary, hepatocellular carcinoma (HCC), glioma, pancreatic cancer and melanoma (6-17). Based on the findings of previous studies, the aim of the present review was to focus on the mechanism underlying the role of G6PD in tumorigenesis and tumor development, as G6PD is hypothesized to become a topic of increased interest with regards to cancer in the future.

\section{Biological function of G6PD in normal cells}

G6PD is encoded by the G6PD gene, which is localized on chromosome $\mathrm{X}$ in the high-density region $\mathrm{xq} 28$, and is $18 \mathrm{~kb}$ in length, consisting of 13 exons and 12 introns. G6PD exhibits significant genetic diversity and the full-length cDNA of the human G6PD is 1,548 bp. The quaternary structure of G6PD is present as a dimer of two identical monomers (18), and the active form is a dimer or tetramer. Each monomer contains 514 amino acids in humans, and has a catalytic coenzyme-binding site and a substrate-binding site that binds to 
glucose-6-phosphate (G6P) $(19,20)$. G6PD is a housekeeping enzyme and is present in all tissues and organs. To the best of our knowledge, the first description of the physiological role and effects of G6PD were presented in 1931 (21). To date, $>400$ biochemical variants and $>200$ genetic variants of G6PD have been described (22). G6PD is an essential enzyme of the PPP, which is a metabolic pathway parallel to glycolysis that catalyzes the dehydrogenation of G6P to produce 6-phosphogluconate. 6-phosphogluconic acid undergoes a series of chemical reactions to produce 6-phosphofructose, which in turn can enter the glycolytic pathway or aerobic oxidation pathways. PPP has three important functions: i) PPP is the only means of using glucose to produce ribose 5-phosphate, and thus provides raw materials for nucleic acid synthesis in vivo. PPP can protect and stabilize DNA, which may make cancer cells more resistant to chemoradiotherapy damage (23-26). ii) PPP provides NADPH and stabilizes the antioxidant defense NADP/NADPH balance. NAPDH acts as an antioxidant and is used to detoxify high levels of reactive oxygen species (ROS) produced during rapid cell multiplication, thereby promoting cell survival $(21,27)$. iii) Pentose enters glycolysis through the PPP (Fig. 1). In mammals, the PPP occurs solely in the cytoplasm, and is found to be most active in the human liver, mammary gland and adrenal cortex. NADPH and pentose supply are prerequisites for runaway growth and proliferation of cells, particularly in tumor cells (28). In addition to serving a role in cell proliferation and aging, G6PD may also be involved in the transmission of apoptotic signals (29). Another study found that highly glycosylated G6PD increases glucose uptake in the PPP and increases its activity. Therefore, blocking the glycosylation of G6PD may reduce the proliferation of cancer cells in vitro and impair tumor growth in vivo (30).

Being a functional pathway independent of glycolysis and oxidative phosphorylation, PPP also serves a crucial role in the liver (31), adipose tissue (32), gonads (33), bone marrow (34), red blood cells and other tissues (1). Since red blood cells do not contain mitochondria, the PPP is the only source of NADPH; therefore, protection from oxidative damage largely relies on G6PD (35). Tumor cell metabolism involves a number of metabolic pathways, including glucose transport, glycolysis, PPP, glutamine metabolism and the electron transport chain (36). Glycolysis refers to the process of transformation of glucose or glycogen into lactic acid and releasing energy through several intermediate steps in the absence of oxygen. Normally, cancer cells metabolize glucose, lactate, glutamine, pyruvic acid, acetate and aliphatic acids at markedly higher rates compared with normal cells (37). Cancer cells take advantage of conventional oxidative metabolism and glycolytic metabolism at the same time. However, even under conditions of sufficient oxygen, proliferation of cancer cells is marked by increased glycolytic metabolism (38). This phenomenon is termed the Warburg effect. The Warburg effect, first described by the German biochemist Otto Warburg, is a metabolic feature of aerobic glycolysis under conditions of sufficient glucose in tumors $(5,39)$. Since the rate of ATP produced by the subsequent steps of glycolysis is 100 times faster compared with that produced by oxidative phosphorylation, as is seen in cancer, cells that rely on oxidative phosphorylation have an advantage since glucose concentrations are higher $(40,41)$. Although it is somewhat slower to convert glucose to ATP compared with other routes, glucose is the most plentiful nutrient present in the blood, and is a metabolic substrate commonly used by tumor cells (39).

The metabolic biology of tumors is complex, and a growing body of evidence suggests that cancer cells have a unique metabolic program that allows for rapid cell proliferation (42). Previous studies have demonstrated that G6PD expression or enzymatic activity is increased in several types of tumors, including colorectal (43), myeloma (44), bladder (11), breast (45), gastrointestinal (46), esophageal (47) and prostate cancer (13) In addition, the instability of G6PD expression is also associated with the degree of malignancy of the tumor. There is increasing evidence that G6PD deficiency affects nucleated cells and cellular pathophysiology, which includes cell proliferation disorders, accelerating cell senescence, increasing susceptibility to viral infections and impairing embryonic development $(48,49)$. The energetic and biosynthetic demands of rapidly proliferating cells, and the relatively balanced levels of ROS regulated by G6PD, may highlight a means of treatment for patients with cancer.

\section{Abnormal status and function of G6PD in cancer cells}

The nutrient demands and energy flow rates of tumor cells are often higher compared with those of normal cells. It was previously confirmed that regulation of tumor cell metabolism may affect the status of the cancer (50). Rapidly dividing cancer cells require three basic metabolic events: The formation of ATP, macromolecular synthesis and cell assembly, and an appropriate cellular redox environment (51). G6PD serves a key role in maintaining a normal redox potential in cells by reducing $\mathrm{NADP}^{+}$to NADPH in the PPP, the dysregulation of which results in insufficient antioxidant defense (52). Changes in the G6PD state are associated with numerous pathophysiological cellular alterations and diseases, including oxygen deficits (53), inflammation (54), infection (55), septicemia (56), diabetes (7), high blood pressure (57) and kidney diseases (14), amongst others. G6PD affects tumor development by regulating several metabolic pathways $(14,54)$. The expression and activity of G6PD has been shown to be associated with the degree of malignancy of a variety of tumors. It has been demonstrated that blocking $80 \%$ of the G6PD activity in tumor cells significantly reduced cell proliferation, migration, invasion, and colony-formation; in addition, tumor cell apoptosis was increased (58). Using GEPIA (version 2019; gepia.cancer-pku. cn) combined with customizable functional analysis (such as tumor/normal tissue differences) to examine and mine data on multiple types of tumors in Genotype Tissue Expression (gtexportal.org/home/) and The Cancer Genome Atlas (portal. gdc.cancer.gov/), the clinical role of G6PD was further explored (Fig. 2A and B). Marked alterations of G6PD gene expression was observed in samples from 9 types of tumors [cholangio carcinoma, colon adenocarcinoma, acute myeloid leukemia (AML), HCC, rectal adenocarcinoma, pancreatic adenocarcinoma, cutaneous melanoma, stomach adenocarcinoma and testicular tumor] compared with normal tissues (Fig. 2A). Furthermore, overall survival analysis revealed that G6PD overexpression was associated with a poor prognosis in certain types of cancer, including mesothelioma, invasive breast carcinoma, HCC, AML and low-grade brain glioma 

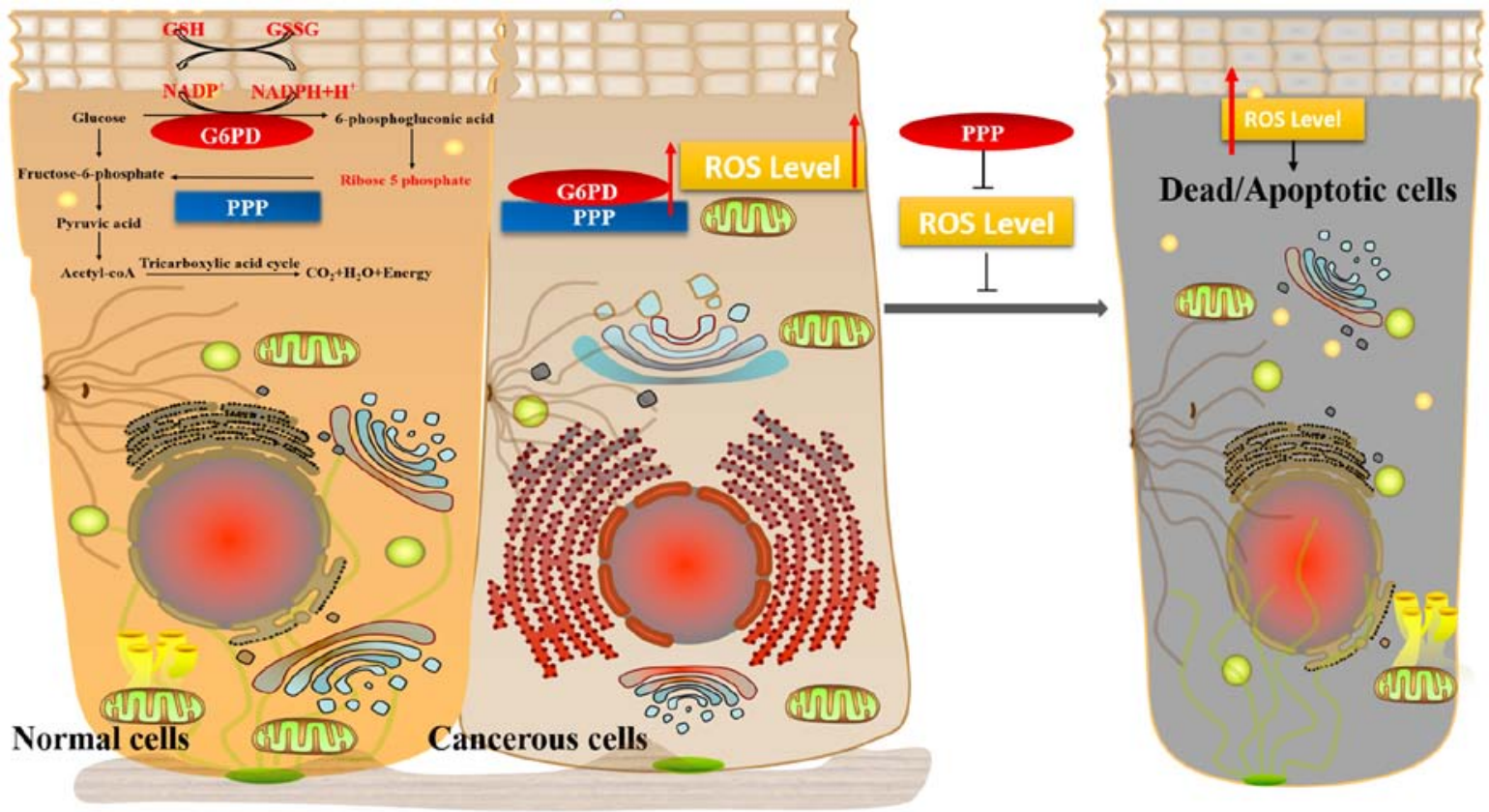

Figure 1. G6PD participates in the PPP in the cytoplasm. G6PD is a key enzyme of the PPP. Glucose metabolism via this pathway primarily produces NADPH and ribose 5-phosphate, which are raw materials for required biosynthesis of other components, and also serve an antioxidant role. The function of ROS in cells is dependent on its levels. Disruption of the ROS balance promotes tumorigenesis and cell death. G6PD, glucose-6-phosphate dehydrogenase; PPP, pentose phosphate pathway; ROS, reactive oxygen species.

(Fig. 2B). Thus, abnormal expression of GP6D is a common finding observed in tumorigenesis, and G6PD is potentially carcinogenic.

Studies on several types of cancer have demonstrated that overexpression of G6PD promotes tumorigenesis and development (summarized in Table I).

Liver cancer cells. In HCC, the phosphatase and tensin homologue (PTEN) signaling pathway is downregulated compared with normal tissues, and its ability to inhibit tumorigenesis is reduced (59). PTEN can inhibit the formation of dimers of the G6PD holoenzyme (60). In advanced stage liver cancer, the expression of G6PD is significantly increased, whereas expression of PTEN is decreased (60). Huh-sh-heterogeneous nuclear ribonucleoprotein (hnRNPK) is known to regulate G6PD-mRNA splicing. It has been demonstrated that T-cell leukemia 1 (Tcl1) affects cell resistance in HCC. Tcl1 directly interacts with hnRNPK in vitro to competitively inhibit the binding of hnRNPK and G6PD. Conversely, increasing evidence is indicating that PTEN disrupts the interaction between Tcll and hnRNPK by inactivating Tcl1 (59). In summary, PTEN induces the expression of G6PD through the Tcl1/hnRNPK/G6PD axis, and thus promotes hepatocarcinogenesis.

In HCC cell lines, it was found that the number of $\beta$-galactosidase-positive cells and expression of p21 (a classical aging marker) increased significantly following G6PD gene knockout, which indicated that the decrease of G6PD delayed the growth of tumor cells (60). The possible implications of this in the treatment of liver cancer is that G6PD inhibition may increase the sensitivity of liver cancer cells to chemotherapeutic drugs (61). Chronic hepatitis B virus (HBV) infection is considered to be involved in the pathogenesis of
HCC. Therefore, the role of G6PD in HBV is also associated with its effect on liver cancer. It has been reported that G6PD may be associated with HBV replication, due to the fact that small interfering RNA-mediated silencing of G6PD reduced HBV production. In addition, when G6PD was silenced, the concentration of HBsAg and $\mathrm{HBeAg}$ secreted in the supernatant was also significantly reduced (62).

Kidney cancer. Renal cell carcinoma (RCC) is the most common type of renal malignancy, accounting for $\sim 3 \%$ of all types of tumors $(63,64)$. RCC is the most aggressive type of urinary tract tumor $(63,65)$. Several studies have concluded that RCC can be viewed as a metabolic disease, the occurrence of which is affected by metabolic changes (66-68). G6PD is not only upregulated in all types of RCC specimens, but also exhibits increased activity in RCC cells (52). Elevated G6PD expression is associated with shorter overall survival. It has been confirmed that the median survival of the patients with high G6PD expression was significantly shorter compared with that of patients with low G6PD expression (69). G6PD overexpression promotes RCC cell proliferation, whereas G6PD silencing reduces the rate of RCC cell proliferation in vitro and inhibits xenograft tumor development in vivo (70). It was previously demonstrated that G6PD may promote tumorigenesis by increasing the rate of proliferation and enhancing antioxidant defense (71), whereas G6PD disorders render tumor cells more adaptable to the immune response and more aggressive (72). The pathways involving G6PD in the proliferation of renal cancer cells are as follows: i) G6PD stimulates ROS production through NADPH oxidase 4 (NOX4); ii) ROS accumulation increases phospho-(p-)signal transducer and activator of transcription 3 (STAT3); and iii) G6PD activates p-STAT3/STAT3 signaling and enhances cyclin D1 expression (73). Briefly, 


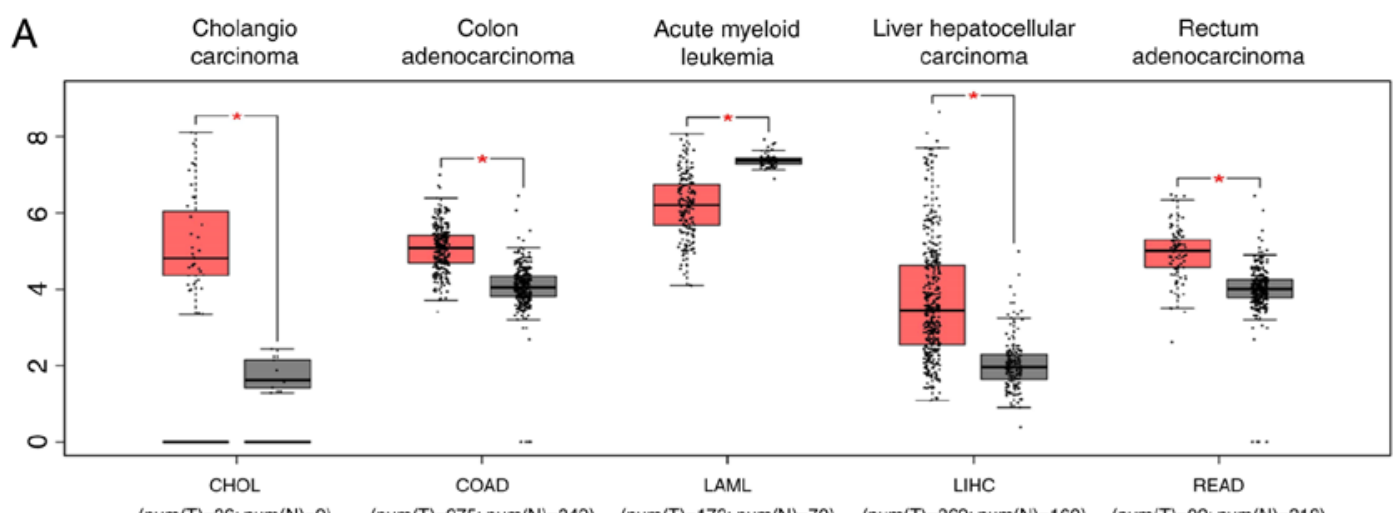

$(\operatorname{num}(\mathrm{T})=36 ; \operatorname{num}(\mathrm{N})=9) \quad(\operatorname{num}(\mathrm{T})=275 ; \operatorname{num}(\mathrm{N})=349) \quad(\operatorname{num}(\mathrm{T})=173 ; \operatorname{num}(\mathrm{N})=70) \quad($ num $(\mathrm{T})=369 ; \operatorname{num}(\mathrm{N})=160) \quad($ num $(\mathrm{T})=92 ; \operatorname{num}(\mathrm{N})=318)$

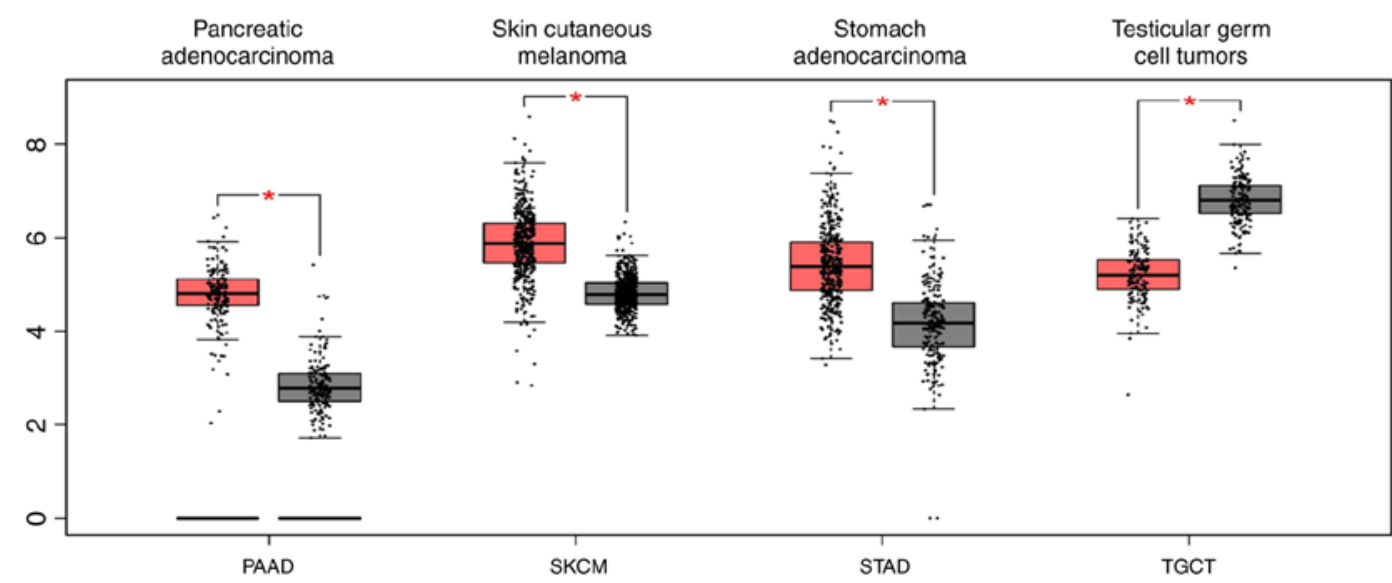

(num $(T)=179 ; \operatorname{num}(\mathrm{N})=171) \quad($ num $(\mathrm{T})=461 ; \operatorname{num}(\mathrm{N})=558) \quad(\operatorname{num}(\mathrm{T})=408 ; \operatorname{num}(\mathrm{N})=211) \quad($ num $(\mathrm{T})=137 ; \operatorname{num}(\mathrm{N})=165)$
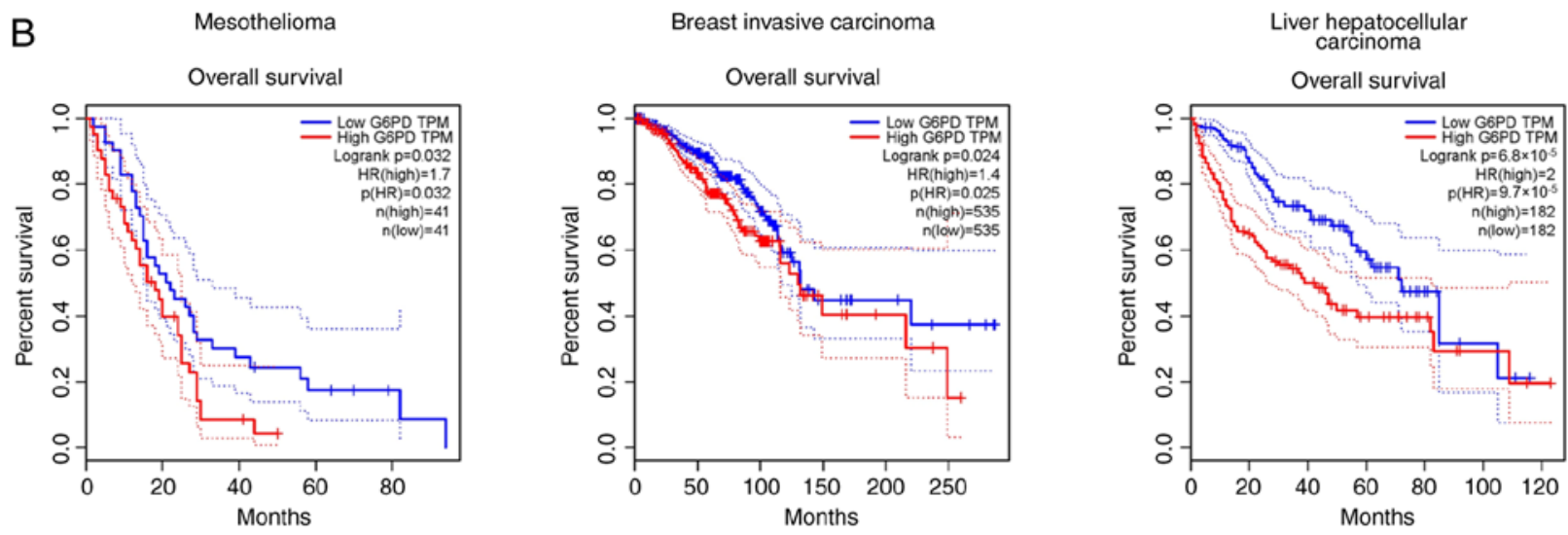

Acute myeloid leukemia

Brain lower grade glioma
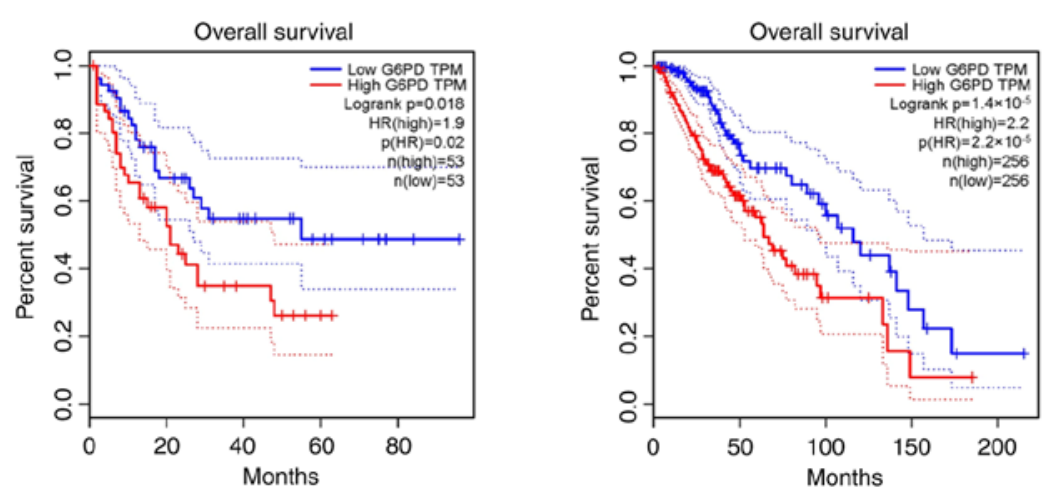

Figure 2. Association between the expression of G6PD and cancer. (A) Expression of G6PD and (B) association between G6PD and overall survival of patients with cancer. G6PD, glucose-6-phosphate dehydrogenase; CHOL, cholangiocarcinoma; BRCA, Breast invasive carcinoma; COAD, colon adenocarcinoma; HCC, hepatocellular carcinoma; AML, acute myeloid leukemia; LGG, low-grade glioma of the brain; MESO, mesothelioma; PAAD, pancreatic adenocarcinoma; READ, rectal adenocarcinoma; CM, cutaneous melanoma; STAD, stomach adenocarcinoma; TGCT, testicular germ cell tumors; TPM, transcripts per million; T, tumor tissue; $\mathrm{N}$, normal tissue; HR, hazard ratio. ${ }^{*} \mathrm{P}<0.05$. 
Table I. G6PD expression in different types of tumors.

\begin{tabular}{|c|c|c|c|c|}
\hline First author, year & Cancer & Impact of G6PD upregulation & Mechanism & (Refs.) \\
\hline Hong, 2013 & Hepatocellular carcinoma & Liver cancer progression & $\begin{array}{l}\text { PTEN affects G6PD active } \\
\text { dimer formation via } \\
\text { Tcl1/hnRNPK/G6PD }\end{array}$ & $(60)$ \\
\hline Zhang, 2017 & Renal cell carcinoma & $\begin{array}{l}\text { Upregulating the proliferation } \\
\text { rate; increasing oxidative } \\
\text { stress; altering the cell cycle }\end{array}$ & $\begin{array}{l}\text { Activation of aG6PD/ROS/ } \\
\text { p-STAT3/Cyclin D1 axis }\end{array}$ & $(70)$ \\
\hline $\mathrm{Xu}, 2016$ & Leukemia & $\begin{array}{l}\text { Increasing proliferation and } \\
\text { clonogenic activity; } \\
\text { cell invasion }\end{array}$ & $\begin{array}{l}\text { SIRT2 promotes NADPH } \\
\text { production by deacetylating } \\
\text { G6PD }\end{array}$ & $(74)$ \\
\hline $\begin{array}{l}\text { Lu, } 2018 \\
\text { Chow, } 2010\end{array}$ & Others & $\begin{array}{l}\text { Lymph node metastasis; } \\
\text { recurrence; lethal; metastasis }\end{array}$ & Summarized in Fig. 4 & $(61,65)$ \\
\hline
\end{tabular}

G6PD can stimulate RCC tumorigenesis in vivo and in vitro by activating the G6PD/ROS/p-STAT3/cyclin D1 signaling pathway in RCC (70).

Leukemia. A number of studies on hematological malignancies have investigated the role of G6PD. It has been reported that NADPH produced by G6PD may be used for lipogenic reactions in leukemia cells (74). AML is a hematological malignancy and it is the most common type of adult acute leukemia (75), characterized by abnormal growth of myeloid progenitor cells and inhibition of cell differentiation (76). PPP, which is closely associated with glycolysis, is also frequently altered in AML. Glucose catabolism in leukemia cells may be mediated through the PPP rather than the glycolysis pathway, indicating that PPP may serve an important role in leukemia metabolism (74,77-80). It has been observed that AML cells rely on glucose metabolism for survival, and a high-flux of glucose is primarily maintained by PPP (81). The suppression of G6PD abolished glycolysis, weakened the effects of PPP and decreased the glucose utilization rate. As a result, AML cells exhibited arrested growth or death, and became more sensitive to chemotherapeutic drugs (82-84). In vivo mouse models have shown that enhanced glucose uptake accelerates the development of leukemia in vivo $(75,85,86)$. Therefore, it may be concluded that G6PD is involved in tumor invasion by affecting other enzymes.

In terms of protein interactions, the deacetylation of G6PD by NAD-dependent deacetylase sirtuin 2 (SIRT2) can enhance the production of NADPH and promote the proliferation of leukemia cells (74). It is hypothesized that the binding of G6PD and SIRT2 is disrupted in heat shock protein 27 (HSPB1-L) knockout cells (87). When HSPB1 expression increases, it can promote the binding of SIRT2 and G6PD, in-turn affecting tumor cell proliferation. By activating the phosphoinositide 3-kinase/Akt/mammalian target of rapamycin signaling pathway, the activity of G6PD is regulated by sterol-regulatory-element-binding protein $1 \mathrm{c}$, which ultimately promotes tumor cell transformation (28).
Other type of cancer. The role of G6PD in several other types of cancer are summarized below. In gastric cancer, the expression levels of G6PD protein was found to be associated with the Tumor-Node-Metastasis stage. The rate of G6PD protein expression in gastric cancer tissues with positive lymph node metastasis was also higher compared with that in lymph node-negative patients $(46,88)$. Colorectal cancer (CRC) is the third most commonly diagnosed type of cancer in Western countries. Moreover, the morbidity rates of CRC have rapidly increased in China over the past two decades $(61,89,90)$. It has been reported that G6PD expression is upregulated in CRC cells and patient specimens. Breast cancer has the highest incidence amongst all types of cancer in women, and remains one of the leading causes of cancer-related death (91). Upregulated expression of G6PD is considered a predictor of a high risk of recurrence and metastasis in patients with breast cancer (92). In prostate cancer, G6PD has been used as a biomarker of diagnosis and prognosis for 30 years (93). G6PD activity in patients with prostate cancer is 4-fold higher compared with that in patients with benign prostatic hyperplasia $(93,94)$. Previous studies have shown that the G6PD levels increase via the PPP in prostate cancer (95-97). In glioma, the activity and content of G6PD affects the efficacy of chemotherapy and radiotherapy $(52,98)$. When human melanoma was investigated using a G6PD knockdown xenograft mouse model, it was observed that G6PD expression was closely associated with tumor formation, size and weight (99). In bladder cancer, knockdown of G6PD inhibits tumor cell proliferation and colony formation (11).

Therefore, G6PD expression is frequently found to be elevated in several different types of cancer, and its internal mechanisms of action have become the focus of increasing attention.

\section{Role of G6PD in cancer and the related networks}

The mechanisms through which G6PD regulates tumor development are yet to be fully elucidated. It is well established 
that G6PD levels are aberrantly elevated in several different types of cancer, and promotes the proliferation of cancer cells through production of ribose-5-phosphate and NADPH as discussed above. The most significant function of NADPH is to form two GSH molecules by reducing one GSH disulfide molecule (100). In turn, GSH may be used to defend against excessive accumulation of ROS (74). ROS, which are produced at low levels by the electron transport chain as part of physiological cellular metabolism, serve a physiologically important role in the regulation of cell signaling, proliferation and differentiation. When ROS production increases above a certain cell-dependent threshold, it may damage cellular components, resulting in cell death (101). Increased generation of ROS in metabolically active cells requires an appropriate level of antioxidants, such as the reduced form of GSH, produced by the PPP (102). It has been shown that ROS can contribute to tumorigenesis by activating various signaling pathways that control cell growth and proliferation (103). However, excess ROS also induces apoptosis (102). If ROS production is higher than the antioxidant defense capacity of the cell, it may lead to oxidative stress, thereby causing cell death. Furthermore, as an organisms ages, the capacity to repair ROS-induced injury becomes gradually weaker and the accumulation of ROS in vivo results in terminal damage (100). That is, when the expression or activity of G6PD gradually decreases, the antioxidant ability of the PPP is weakened and the levels of ROS progressively increases. G6PD participates in the PPP to promote the production of GSH. As a classic antioxidant, GSH can defend against excessive production of ROS, thereby maintaining cells, particularly tumor cells, in a proliferating state (Fig. 1). To resist oxidative stress, cancer cells have enhanced antioxidant programs (50). Thus, a key molecule produced as a result of altered cancer metabolism is NADPH, which is an antioxidant and forms part of the defense against ROS (50). There are two primary forms of NADPH production: i) NADH and $\mathrm{NADP}^{+}$generate NADPH by catalysis of mitochondrial transhydrogenase and ii) $\mathrm{NADP}^{+}$produces NADPH by catalysis of a variety of $\mathrm{NADP}^{+}$-dependent enzymes (104). Currently, increasing evidence is suggesting that $\mathrm{NAD}\left(\mathrm{NAD}^{+}\right.$or $\left.\mathrm{NADH}\right)$ and NADP (NADP ${ }^{+}$or NADPH) can influence various biological processes, including energy metabolism, mitochondrial functions, calcium homeostasis, antioxidation/generation of oxidative stress, gene expression, immunological functions, aging and cell death (104-107). In fact, the sources of NADPH generation may determine the different biological effects of NADPH: The NADPH catalyzed by the mitochondrial enzymes primarily contribute to antioxidation and biosynthesis, whereas the NADPH catalyzed by the cytosolic enzymes contributes to NADPH oxidase-dependent ROS generation when NADPH oxidase (NOX) is activated (104). The NOX family consists of seven enzymatic isoforms, and is an enzyme complex with the unique function of producing superoxide anions and ROS through consumption of NADPH (108). The process of NOX-mediated production of ROS is primarily through one-electron reduction of oxygen to superoxide depending on NADPH (109). NADPH is produced by glucose, once inside the cells as an intermediate of glycolysis, to generate glucose 6-phosphate (G6P). G6P continues to pass through the glycolytic pathway or is split with a hexose-phosphate shunt to produce NADPH (108). In tumor cells, ROS promotes cell proliferation via redox reactions. ROS modulates several signaling pathways associated with cellular transformation, inflammation, tumor survival, proliferation, invasion, angiogenesis and metastasis of cancer (110). For maintaining cell proliferation, the levels of ROS in cancer cells is elevated compared with normal cells $(105,106,111,112)$. Excessive accumulation of ROS may lead to cell apoptosis or even death; however, tumor cells may maintain proliferation without being affected by ROS, primarily due to the ability of anti-oxidative stress with the participation of NADPH $(50,74,101,102)$. In the PPP pathway, NADPH maintains the reduced state of GSH, thereby inducing resistance to ROS (102). This process is involved in the anti-ROS effects of NADPH (102). Therefore, it may be concluded that a moderate increase in G6PD activity is beneficial for avoiding the harmful effects of ROS. Of note, G6PD activity and its expression are increased by oncogenes, such as KRAS (113), and suppressed by tumor suppressors, such as P53 or PTEN $(60,114)$. Below, a summary of the studies investigating the underlying mechanisms, with a focus on proliferation, cell cycle progression, apoptosis, invasion and migration is provided (Fig. 3).

G6PD promotes epithelial-mesenchymal transition (EMT) by activating the STAT3 pathway. and EMT serves a key role in enhancing tumor cell invasion and metastasis (61). G6PD is important for several cellular processes and enzymes using NADPH, including enzymes in the antioxidant system (21), including nitric oxide synthase and superoxide dismutase, both of which are NADPH-dependent enzymes (115) and can promote EMT and invasion of pancreatic cancer cells (116).

Regarding cell apoptosis, the expression levels of Bcl-2 and Bcl-xL, which are both inhibitors of apoptosis, were found to be reduced in cells with low G6PD expression levels. However, the expression of Fas was increased, and Fas can bind to the cytokines of the death receptor TNFRSF6/Fas and induce apoptosis caused by T-cell-mediated cytotoxicity. Athanogene 3 (BAG3) protein directly binds to G6PD to exert a tumor suppressor-like function in HCCs (117). The Bcl-2 associated BAG3 protein is involved in several cellular functions, including cell cycle, autophagy, cell growth and pathogen replication $(118,119)$. Through Bcl-2, BAG3 suppresses dimerization and activity of G6PD. It is hypothesized that G6PD may affect apoptosis by interacting with apoptosis-related factors $(71,99)$.

Although there are no definitive conclusions on the role of G6PD in regulating the cell cycle, the results of other studies in this area are summarized in the present review. It has been established that in cells lacking G6PD, downregulation of the cell cycle proteins cyclin D1 and E, and S100a4 is observed (99). The expression of cyclin D1 is decreased following G6PD knockout (120), and this affected cell growth and division via regulation of the G1/S transition $(63,121)$. Additionally, G6PD overexpression can activate the STAT3 pathway, primarily through increasing the levels of p-STAT3. When the expression of G6PD is low, protein tyrosine kinase (c-SRC) and protein tyrosine phosphatase (SHP2) are suppressed. As c-SRC and SHP2 can regulate the 


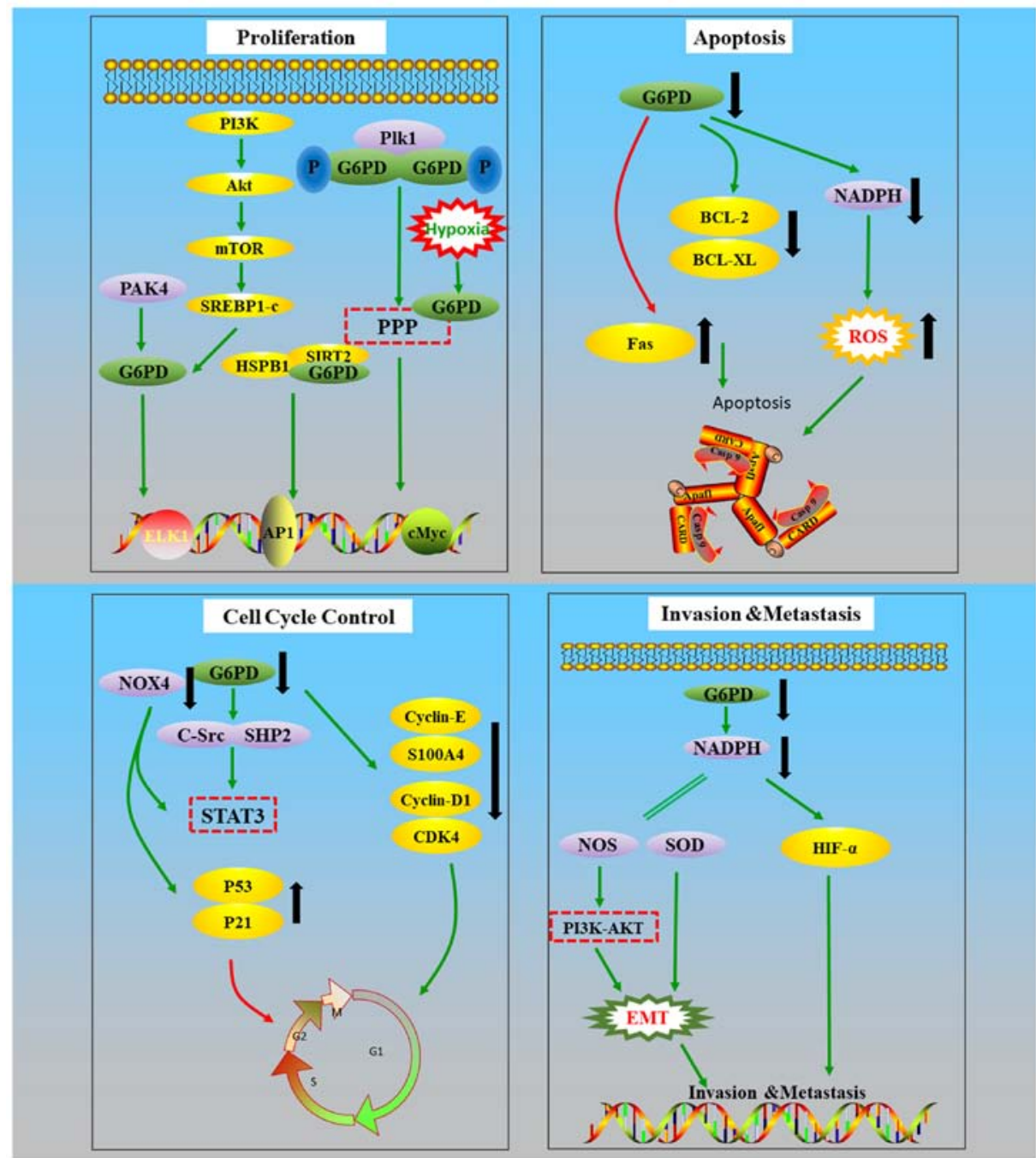

Figure 3. Schematic of the regulatory mechanisms of the involvement of G6PD in cancer, which primarily occurs via four aspects: Cell proliferation, apoptosis, cell cycle progression, and invasion and migration. G6PD, glucose-6-phosphate dehydrogenase; PPP, pentose phosphate pathway; ROS, reactive oxygen species; EMT, epithelial-mesenchymal transition; mTOR, mammalian target of rapamycin; CARD, Caspase recruitment domain; Casp 9, Caspase 9; SREBP1c, sterol-regulatory-element-binding protein 1c; SIRT2, sirtuin 2; HSP-B1, heat shock protein 27; NOX4, NADPH oxidase 4; c-Src, protein tyrosine kinase; SOD, superoxide dismutase; NOS, nitric oxide synthase; STAT3, signal transducer and activator of transcription 3; p, phospho; HIF-1 $\alpha$, hypoxia-inducible factor-1 $\alpha$; SHP2, protein tyrosine phosphatase; PI3K, phosphoinositide 3-kinase.

DNA-binding activity of STAT3, G6PD serves an important indirect role in DNA-binding via the above mentioned pathways, thus affecting cell cycle progression and suppressing cell proliferation (120). After silencing G6PD and NOX4, the expression levels of p53 and p21 were upregulated and the cell cycle was arrested in the G1/S phase. At the same time, the protein levels of cyclin D1 and cyclin-dependent kinase 4 were decreased. Upregulation of p53 may be achieved by downregulating PAK4, resulting in S phase arrest of the cell cycle (122). PAK4 can also directly interact with G6PD, and then enhance the activity of G6PD to promote glucose intake and the production of NADPH, thereby promoting tumor growth (123). These results indicate that the cell cycle is also affected by this pathway. Polo-like kinase 1 (Plk1), a serine/ threonine kinase, regulates cell mitosis (124). G6PD is activated when Plk1 binds to G6PD. Moreover, G6PD-mediated PPP may be involved in the regulation of the cell cycle by Plk1 (124). By contrast, p53 inhibits the proliferation of tumor cells by repressing the formation of G6PD dimers (70). The mechanism by which G6PD affects the cell cycle is debated. In G6PD-deficient cells, there was a noticeable delay in cell proliferation, which was found to resemble cell senescence (29).

In an anoxic environment, G6PD also serves a regulatory role in the survival of tumor cells. Abnormal acetylation was found to be associated with the growth and invasion of cancer cells in vitro and in vivo $(125,126)$. Under hypoxic conditions, the glycosylation of G6PD is activated, thus activating the PPP (30). Hypoxia-inducible factor- $1 \alpha$ (HIF-1 $\alpha$ ) is present in abundant quantities in a variety of human tumor cells, and serves an important role in promoting tumor angiogenesis, accelerating tumor cell proliferation, and promoting invasion and metastasis (127). It has been suggested that the G6PD gene may impair the stability and expression of HIF-1 $\alpha$ by downregulating the levels of NADPH, which may in-turn affect the hypoxia response of tumor cells (127). However, the detailed mechanisms by which G6PD affects tumor cells remain unknown. 
Investigation of the mechanism by which G6PD promotes tumorigenesis and tumor development may improve our understanding of the association between G6PD and cancer, and may also provide theoretical guidance for targeted therapy.

\section{G6PD and cancer treatment}

Successful treatment, recurrence and resistance of cancer are commonly encountered problems. The results of traditional methods of cancer treatment (including surgical chemotherapy, radiotherapy, use of traditional Chinese medicines and biological therapy) are not optimal. Although first-line treatment with cytotoxic chemotherapy has achieved a high rate of remission, the majority of the patients eventually succumb to the disease. In order to increase the cure rates, improve the prognosis, and to minimize the suffering of the patients, more effective and less toxic cancer treatments are urgently required. Molecular targeted cancer treatment may hold promise as a therapeutic approach. The expression of G6PD may represent a potential treatment option. As the effect of G6PD activity on the cell cycle has been demonstrated, several pathways that involve G6PD may be targeted to improve the efficacy of treatment. The interactions between G6PD and multiple signaling pathways directly or indirectly, affects cell cycle progression of tumor cells, eventually altering cell proliferation or apoptosis. Ongoing studies in different types of cancer, and investigation of G6PD specificity may highlight potential avenues to overcome these problems. The PPP may also affect the adaptation of tumor cells to the changes in the microenvironment, and enable them to survive longer compared with normal cells $(128,129)$. Although the detailed mechanisms of the functional mechanisms of G6PD are not fully understood, further investigations should address the following possibilities: i) The defense of tumor cells against oxidative stress may be weakened by inhibiting G6PD to interrupt the energy supply, leading to increased sensitivity of tumor cells to oxidants. ii) Based on the principle of metabolic reprogramming, by adjusting the activity of G6PD to affect the role of PPP in biosynthesis, the resistance of tumor cells to drugs may be overcome. iii) Alternatively, certain types of cancer cells may adapt to high levels of carcinogenic signals by destroying their aging or apoptotic induction circuits. G6PD may be involved in this process, or it may enable tumor cells to escape certain events that have a negative effect on cancer cell proliferation.

The metabolic reprogramming alters the tumor microenvironment affecting cancer cells and other immune cells, such as macrophages, $\mathrm{T}$ lymphocytes and myeloid-derived suppressor cells $(5,130)$. Targeting metabolic transformation or metabolism-regulated signaling pathways in tumor development may be a potential anticancer treatment strategy, alone or in combination with immunotherapy. At present, as one of the basic characteristics of tumor cells, metabolic programming has been recognized as a new cancer hallmark (130). In order to meet the needs of rapid proliferation for energy and to counteract the increased oxidative stress, tumor cells are reprogrammed, and this includes changes to their glucose, fat and other metabolic pathways. Ribose-5-phosphate and NADPH are important products catalyzed by G6PD. The former is the raw material of nucleic acid synthesis (108), which is the basis of cell division, proliferation and maturation, whereas the latter is involved in fatty acid, nucleic acid and ROS metabolism, amongst other functions, acting as a hydrogen donor in all these processes (104). In this context, G6PD serves an important role in promoting biosynthesis, and an increase of G6PD activity further promotes the activity of PPP. As a result, a large quantity of glucose is consumed, which is involved in numerous biosynthetic processes and this produces a large set of reductants (23-26). Thus, it is hypothesized that metabolic reprogramming by PPP may be of value as a biomarker for detection of cancer and as a target for the development of novel anticancer treatments (36).

G6PD inhibitors have been developed, and 1-bromoacety $1-3,3$-dinitroazetidine (RRx-001) is one of these. RRx-001 is both a G6PD inhibitor and a multifunctional anticancer drug that has been tested in phase III clinical trials (131). RRx-001 has been evaluated in $\sim 300$ patients in 9 clinical trials (131), and the results were promising, with no associated hematological toxicities reported. Based on the proven antitumor activity and favorable toxicity profile in the phase II clinical trial, RRx-001 has been approved by the FDA and EMA, and may be used in phase III multi-center studies in subjects with relapsed/refractory solid tumors $(131,132)$. However, in vitro experiments have shown that high concentrations $(7-10 \mu \mathrm{M})$ of RRx-001 reduce the viability of peripheral mononuclear blood cells by $30-70 \%$, indicating that normal cells are not entirely refractory to RRx-001 (133). Polydatin is another known G6PD inhibitor, which may cause ROS accumulation and enhanced endoplasmic reticulum stress by inhibiting G6PD (134). Experiments have shown that polydatin is non-toxic to animals at a dose of $200 \mathrm{mg} / \mathrm{kg}$ (134). Phase II clinical trials demonstrated that it is also well tolerated in humans at a dose of $40 \mathrm{mg}$ twice a day for 90 days. Therefore, polydatin may be used with confidence in clinical treatment (134). Thus, it appears that the toxicity of G6PD inhibitors to normal cells is limited, but not completely absent. However, G6PD is still hypothesized to serve as a promising target for anti-cancer treatments.

\section{Conclusion}

In summary, G6PD may be characterized as a participant rather than a bystander in the process of tumorigenesis, and downregulation of G6PD may enhance the sensitivity of certain types of tumors to chemotherapeutic drugs. Therefore, G6PD may serve as an important target for cancer therapy and for overcoming resistance to chemotherapy.

\section{Acknowledgements}

We would like to thank Ms Mengjie Guo (School of Medicine and Holistic Integrative Medicine, Nanjing University of Chinese Medicine, Nanjing, China) for her outstanding efforts in the revision of this manuscript.

\section{Funding}

This work was supported by grants from the National Natural Science Foundation of China (grant nos. 81670200 and 81970196); Innovation Team of Six Talent Peaks Project in 
Jiangsu Province (grant no. TD-SWYY-015); and A Project Funded by the Priority Academic Program Development of Jiangsu Higher Education Institutions (Integration of Chinese and Western Medicine).

\section{Availability of data and materials}

The data used for the analyses described in this manuscript were obtained from the GTEx (version 2019; gepia. cancer-pku.cn) and The Cancer Genome Atlas (portal.gdc. cancer.gov/).

\section{Authors' contributions}

YY and CG conceived the subject of the review. RL and WW wrote the manuscript, analyzed the data, and plotted the graphs. CG and YY edited the manuscript. All authors have read and approved the final manuscript.

\section{Ethics approval and consent to participate}

Not applicable.

\section{Patient consent for publication}

Not applicable.

\section{Competing interests}

The authors declare that they have no competing interests.

\section{References}

1. Luzzatto L and Arese P: Favism and Glucose-6-phosphate dehydrogenase deficiency. N Engl J Med 378: 60-71, 2018.

2. Yang HC, Wu YH, Liu HY, Stern A and Chiu DT: What has passed is prolog: New cellular and physiological roles of G6PD. Free Radic Res 50: 1047-1064, 2016.

3. Luzzatto L and Seneca E: G6PD deficiency: A classic example of pharmacogenetics with on-going clinical implications. Br J Haematol 164: 469-480, 2014.

4. Longo L, Vanegas OC, Patel M, Rosti V,LiH, Waka J, Merghoub T, Pandolfi PP, Notaro R, Manova K and Luzzatto L: Maternally transmitted severe glucose 6-phosphate dehydrogenase deficiency is an embryonic lethal. EMBO J 21: 4229-4239, 2002.

5. Sun L, Suo C, Li ST, Zhang H and Gao P: Metabolic reprogramming for cancer cells and their microenvironment: Beyond the Warburg Effect. Biochim Biophys Acta Rev Cancer 1870: 51-66, 2018.

6. Ho HY, Cheng ML and Chiu DT: Glucose-6-phosphate dehydrogenase-beyond the realm of red cell biology. Free Radic Res 48: 1028-1048, 2014.

7. Heymann AD, Cohen Y and Chodick G: Glucose-6-phosphate dehydrogenase deficiency and type 2 diabetes. Diabetes Care 35: e58, 2012.

8. Carette C, Dubois-Laforgue D, Gautier JF and Timsit J: Diabetes mellitus and glucose-6-phosphate dehydrogenase deficiency: from one crisis to another. Diabetes Metab 37: 79-82, 2011.

9. Wan GH, Tsai SC and Chiu DT: Decreased blood activity of glucose-6-phosphate dehydrogenase associates with increased risk for diabetes mellitus. Endocrine 19: 191-195, 2002.

10. Fang Z, Jiang C, Feng Y, Chen R, Lin X, Zhang Z, Han L, Chen X, $\mathrm{Li} \mathrm{H}$, Guo Y and Jiang W: Effects of G6PD activity inhibition on the viability, ROS generation and mechanical properties of cervical cancer cells. Biochim Biophys Acta 1863: 2245-2254, 2016.

11. Chen X, Xu Z, Zhu Z, Chen A, Fu G, Wang Y, Pan H and Jin B: Modulation of G6PD affects bladder cancer via ROS accumulation and the AKT pathway in vitro. Int J Oncol 53: 1703-1712, 2018 .
12. Ai G, Dachineni R, Kumar DR, Alfonso LF, Marimuthu S and Bhat GJ: Aspirin inhibits glucose-6-phosphate dehydrogenase activity in HCT 116 cells through acetylation: Identification of aspirin-acetylated sites. Mol Med Rep 14: 1726-1732, 2016.

13. Chen J, Cao S, Situ B, Zhong J, Hu Y, Li S, Huang J, Xu J, Wu S, Lin $\mathrm{J}$, et al: Metabolic reprogramming-based characterization of circulating tumor cells in prostate cancer. J Exp Clin Cancer Res 37: 127, 2018.

14. Spencer NY and Stanton RC: Glucose 6-phosphate dehydrogenase and the kidney. Curr Opin Nephrol Hypertens 26: 43-49, 2017.

15. Shan CL, Lu Z, Li Z, Sheng H, Fan J, Qi Q, Liu S and Zhang S: 4-hydroxyphenylpyruvate dioxygenase promotes lung cancer growth via pentose phosphate pathway (PPP) flux mediated by LKB1-AMPK/HDAC10/G6PD axis. Cell Death Dis 10: 525, 2019.

16. Xu Y, Gao W, Zhang Y, Wu S, Liu Y, Deng X, Xie L, Yang J, $\mathrm{Yu} \mathrm{H}, \mathrm{Su} \mathrm{J}$ and Sun L: ABT737 reverses cisplatin resistance by targeting glucose metabolism of human ovarian cancer cells. Int J Oncol 53: 1055-1068, 2018.

17. Minchenko OH, Garmash IA, Minchenko DO, Kuznetsova AY and Ratushna OO: Inhibition of IRE1 modifie s hypoxic regulation of G6PD, GPI, TKT, TALDO1, PGLS and RPIA genes expression in U87 glioma cells. Ukr Biochem J 89: 38-49, 2017.

18. Kiani F, Schwarzl S, Fischer S and Efferth T: Three-dimensional modeling of Glucose-6-phosphate dehydrogenase-deficient variants from German ancestry. PLoS One 2: e625, 2007.

19. Kotaka M, Gover S, Vandeputte-Rutten L, Au SW, Lam VM and Adams MJ: Structural studies of glucose-6-phosphate and $\mathrm{NADP}^{+}$binding to human glucose-6-phosphate dehydrogenase. Acta Crystallogr D Biol Crystallogr 61: 495-504, 2005.

20. Au SW, Gover S, Lam VM and Adams MJ: Human glucose-6-phosphate dehydrogenase: The crystal structure reveals a structural NADP $(+)$ molecule and provides insights into enzyme deficiency. Structure 8: 293-303, 2000.

21. Stanton RC: Glucose-6-phosphate dehydrogenase, NADPH, and cell survival. IUBMB life 64: 362-369, 2012.

22. Minucci A, Moradkhani K, Hwang MJ, Zuppi C, Giardina B and Capoluongo E: Glucose-6-phosphate dehydrogenase (G6PD) mutations database: Review of the 'old' and update of the new mutations. Blood Cells Mol Dis 48: 154-165, 2012.

23. Ramos-Montoya A, Lee WN, Bassilian S, Lim S, Trebukhina RV, Kazhyna MV, Ciudad CJ, Noé V, Centelles JJ and Cascante M: Pentose phosphate cycle oxidative and nonoxidative balance: A new vulnerable target for overcoming drug resistance in cancer. Int J Cancer 119: 2733-2741, 2006

24. Brizel DM, Schroeder T, Scher RL, Walenta S, Clough RW, Dewhirst MW and Mueller-Klieser W: Elevated tumor lactate concentrations predict for an increased risk of metastases in head-and-neck cancer. Int J Radiat Oncol Biol Phys 51: 349-353, 2001.

25. Seyfried TN, Sanderson TM, El-Abbadi MM, McGowan R and Mukherjee P: Role of glucose and ketone bodies in the metabolic control of experimental brain cancer. Br J Cancer 89: 1375-1382, 2003.

26. Xu RH, Pelicano H, Zhou Y, Carew JS, Feng L, Bhalla KN, Keating MJ and Huang P: Inhibition of glycolysis in cancer cells: A novel strategy to overcome drug resistance associated with mitochondrial respiratory defect and hypoxia. Cancer Res 65: 613-621, 2005.

27. Patra KC and Hay N: The pentose phosphate pathway and cancer. Trends Biochem Sci 39: 347-354, 2014.

28. Cernaj IE: Simultaneous dual targeting of Par-4 and G6PD: A promising new approach in cancer therapy? Quintessence of a literature review on survival requirements of tumor cells. Cancer Cell Int 16: 87, 2016.

29. Ho HY, Cheng ML and Chiu DT: Glucose-6-phosphate dehydrogenase-from oxidative stress to cellular functions and degenerative diseases. Redox Rep 12: 109-118, 2013

30. Rao X, Duan X, Mao W, Li X, Li Z, Li Q, Zheng Z, Xu H, Chen M, Wang PG, et al: O-GlcNAcylation of G6PD promotes the pentose phosphate pathway and tumor growth. Nat Commun 6: 8468, 2015.

31. Jin ES, Sherry AD and Malloy CR: Interaction between the pentose phosphate pathway and gluconeogenesis from glycerol in the liver. J Biol Chem 289: 32593-32603, 2014.

32. Park YJ, Choe SS, Sohn JH and Kim JB: The role of glucose-6-phosphate dehydrogenase in adipose tissue inflammation in obesity. Adipocyte 6: 147-153, 2017. 
33. Keran EE and Barker KL: Regulation of glucose-6-phosphate dehydrogenase activity in uterine tissue in organ culture. Endocrinology 99: 1386-1397, 1976.

34. Chandra R, Villanueva E, Feketova E, Machiedo GW, Haskó G, Deitch EA and Spolarics Z: Endotoxemia down-regulates bone marrow lymphopoiesis but stimulates myelopoiesis: The effect of G6PD deficiency. J Leukoc Biol 83: 1541-1550, 2008.

35. van Zwieten R, Verhoeven AJ and Roos D: Inborn defects in the antioxidant systems of human red blood cells. Free Radic Biol Med 67: 377-386, 2014.

36. Schulze A and Harris AL: How cancer metabolism is tuned for proliferation and vulnerable to disruption. Nature 491: 364-373, 2012.

37. Martinez-Outschoorn UE, Peiris-Pages M, Pestell RG, Sotgia F and Lisanti MP: Cancer metabolism: A therapeutic perspective. Nat Rev Clin Oncol 14: 11-31, 2017.

38. Icard P, Shulman S, Farhat D, Steyaert JM, Alifano M and Lincet H: How the Warburg effect supports aggressiveness and drug resistance of cancer cells? Drug Resist Updat 38: 1-11, 2018.

39. Boroughs LK and DeBerardinis RJ: Metabolic pathways promoting cancer cell survival and growth. Nat Cell Biol 17: 351-359, 2015.

40. Pfeiffer T, Schuster S and Bonhoeffer S: Cooperation and competition in the evolution of ATP-producing pathways. Science 292: 504-507, 2001.

41. Cox E and Bonner J: Ecology. The advantages of togetherness. Science 292: 448-449, 2001.

42. Israelsen WJ and Vander Heiden MG: ATP consumption promotes cancer metabolism. Cell 143: 669-671, 2010.

43. Ju HQ, Lu YX, Wu QN, Liu J, Zeng ZL, Mo HY, Chen Y, Tian T, Wang Y, Kang TB, et al: Disrupting G6PD-mediated Redox homeostasis enhances chemosensitivity in colorectal cancer. Oncogene 36: 6282-6292, 2017.

44. McBrayer SK, Yarrington M, Qian J, Feng G, Shanmugam M, Gandhi V, Krett NL and Rosen ST: Integrative gene expression profiling reveals G6PD-mediated resistance to RNA-directed nucleoside analogues in B-cell neoplasms. PLoS One 7: e41455, 2012.

45. Zhang HS, Zhang ZG, Du GY, Sun HL, Liu HY, Zhou Z, Gou XM, Wu XH, Yu XY and Huang YH: Nrf2 promotes breast cancer cell migration via up-regulation of G6PD/HIF-1 $\alpha /$ Notch1 axis. J Cell Mol Med 23: 3451-3463, 2019.

46. Wang J, Yuan W, Chen Z, Wu S, Chen J, Ge J, Hou F and Chen Z: Overexpression of G6PD is associated with poor clinical outcome in gastric cancer. Tumour Biol 33: 95-101, 2012.

47. Wang X, Li X, Zhang X, Fan R, Gu H, Shi Y and Liu H Glucose-6-phosphate dehydrogenase expression is correlated with poor clinical prognosis in esophageal squamous cell carcinoma. Eur J Surg Oncol 41: 1293-1299, 2015.

48. Yang HC, Chen TL, Wu YH, Cheng KP, Lin YH, Cheng ML, Ho HY, Lo SJ and Chiu DT: Glucose 6-phosphate dehydrogenase deficiency enhances germ cell apoptosis and causes defective embryogenesis in Caenorhabditis elegans. Cell Death Dis 4 e616, 2013.

49. Wu YH, Lee YH, Shih HY, Chen SH, Cheng YC and Tsun-Yee Chiu D: Glucose-6-phosphate dehydrogenase is indispensable in embryonic development by modulation of epithelial-mesenchymal transition via the NOX/Smad3/miR-200b axis. Cell Death Dis 9: 10, 2018

50. Cairns RA, Harris IS and Mak TW: Regulation of cancer cell metabolism. Nat Rev Cancer 11: 85-95, 2011.

51. Tong X, Zhao F and Thompson CB: The molecular determinants of de novo nucleotide biosynthesis in cancer cells. Curr Opin Genet Dev 19: 32-37, 2009.

52. Frederiks WM, Bosch KS, Hoeben KA, van Marle J and Langbein S: Renal cell carcinoma and oxidative stress: The lack of peroxisomes. Acta Histochem 112: 364-371, 2010.

53. Chettimada S, Joshi SR, Alzoubi A, Gebb SA, McMurtry IF, Gupte R and Gupte SA: Glucose-6-phosphate dehydrogenase plays a critical role in hypoxia-induced CD $133^{+}$progenitor cells self-renewal and stimulates their accumulation in the lungs of pulmonary hypertensive rats. Am J Physiol Lung Cell Mol Physiol 307: L545-L556, 2014.

54. Peiró C, Romacho T, Azcutia V, Villalobos L, Fernández E, Bolaños JP, Moncada S and Sánchez-Ferrer CF: Inflammation, glucose, and vascular cell damage: The role of the pentose phosphate pathway. Cardiovasc Diabetol 15: 82, 2016.

55. Wu YH, Tseng CP, Cheng ML, Ho HY, Shih SR and Chiu DT: Glucose-6-phosphate dehydrogenase deficiency enhances human coronavirus 229E infection. J Infect Dis 197: 812-816, 2008.
56. Rostami-Far Z, Ghadiri K, Rostami-Far M, Shaveisi-Zadeh F, Amiri A and Rahimian Zarif B: Glucose-6-phosphate dehydrogenase deficiency (G6PD) as a risk factor of male neonatal sepsis. J Med Life 9: 34-38, 2016.

57. Zhao J, Zhang X, Guan T, Wang X, Zhang H, Zeng X, Dai Q, Wang Y, Zhou L and Ma X: The association between glucose-6-phosphate dehydrogenase deficiency and abnormal blood pressure among prepregnant reproductive-age Chinese females. Hypertens Res 42: 75-84, 2019.

58. Li D, Zhu Y, Tang Q, Lu H, Li H, Yang Y, Li Z and Tong S: A new G6PD knockdown tumor-cell line with reduced proliferation and increased susceptibility to oxidative stress. Cancer Biother Radiopharm 24: 81-90, 2009.

59. Wang XQ, Ongkeko WM, Chen L, Yang ZF, Lu P, Chen KK, Lopez JP, Poon RT and Fan ST: Octamer 4 (Oct4) mediates chemotherapeutic drug resistance in liver cancer cells through a potential Oct4-AKT-ATP-binding cassette G2 pathway. Hepatology 52: 528-539, 2010.

60. Hong XH, Song RP, Song HW, Zheng T, Wang J, Liang Y, Qi S, Lu Z, Song X, Jiang H, et al: PTEN antagonises Tcl1/ hnRNPK-mediated G6PD pre-mRNA splicing which contributes to hepatocarcinogenesis. Gut 63: 1635-1647, 2013.

61. Lu M, Lu L, Dong Q, Yu G, Chen J, Qin L, Wang L, Zhu W and Jia H: Elevated G6PD expression contributes to migration and invasion of hepatocellular carcinoma cells by inducing epithelial-mesenchymal transition. Acta Biochim Biophys Sin (Shanghai) 50: 370-380, 2018

62. Hu H, Ding X, Yang Y, Zhang H, Li H, Tong S, An X, Zhong Q, Liu X, Ma L, et al: Changes in glucose-6-phosphate dehydrogenase expression results in altered behavior of HBV-associated liver cancer cells. Am J Physiol Gastrointest Liver Physiol 307: G611-G622, 2014.

63. Lima MS, Pereira RA, Costa RS, Tucci S, Dantas M, Muglia VF, Ravinal RC and Barros-Silva GE: The prognostic value of cyclin D1 in renal cell carcinoma. Int Urol Nephrol 46: 905-913, 2014

64. Lindblad P: Epidemiology of renal cell carcinoma. Scand J Surg 93: 88-96, 2004.

65. Chow WH, Dong LM and Devesa SS: Epidemiology and risk factors for kidney cancer. Nat Rev Urol 7: 245-257, 2010.

66. Linehan WM, Srinivasan R and Schmidt LS: The genetic basis of kidney cancer: A metabolic disease. Nat Rev Urol 7: 277-285, 2010.

67. Vavallo A, Simone S, Lucarelli G, Rutigliano M, Galleggiante V, Grandaliano G, Gesualdo L, Campagna M, Cariello M, Ranieri E, et al: Pre-existing type 2 diabetes mellitus is an independent risk factor for mortality and progression in patients with renal cell carcinoma. Medicine (Baltimore) 93: e183, 2014.

68. Cancer Genome Atlas Research Network: Comprehensive molecular characterization of clear cell renal cell carcinoma. Nature 499: 43-49, 2013.

69. Zhang Q, Yi X, Yang Z, Han Q, Di X, Chen F, Wang Y, Yi Z, Kuang Y and Zhu Y: Overexpression of G6PD represents a potential prognostic factor in clear cell renal cell carcinoma. J Cancer 8: 665-673, 2017.

70. Zhang Q, Yang Z, Han Q, Bai H, Wang Y, Yi X, Yi Z, Yang L, Jiang L, Song X, et al: G6PD promotes renal cell carcinoma proliferation through positive feedback regulation of p-STAT3. Oncotarget 8: 109043-109060, 2017.

71. Yang HC, Wu YH, Yen WC, Liu HY, Hwang TL, Stern A and Chiu DT: The redox role of G6PD in cell growth, cell death, and cancer. Cells 8: 1055, 2019.

72. Langbein S, Frederiks WM, zur Hausen A, Popa J, Lehmann J, Weiss C, Alken P and Coy JF: Metastasis is promoted by a bioenergetic switch: New targets for progressive renal cell cancer. Int J Cancer 122: 2422-2428, 2008.

73. Shasha L, Priceman SJ, Xin H, Zhang W, Deng J, Liu Y, Huang J, Zhu W, Chen M, Hu W, et al: Icaritin inhibits JAK/STAT3 signaling and growth of renal cell carcinoma. PLoS One 8: e81657, 2013

74. Xu SN, Wang TS, Li X and Wang YP: SIRT2 activates G6PD to enhance NADPH production and promote leukaemia cell proliferation. Sci Rep 6: 32734, 2016.

75. Saito Y, Chapple RH, Lin A, Kitano A and Nakada D: AMPK protects Leukemia-initiating cells in myeloid leukemias from metabolic stress in the bone marrow. Cell Stem Cell 17: 585-596, 2015.

76. Xu Q, Simpson SE, Scialla TJ, Bagg A and Carroll M: Survival of acute myeloid leukemia cells requires PI3 kinase activation. Blood 102: 972-980, 2003. 
77. Chen Y, Xu Q, Ji D, Wei Y, Chen H, Li T, Wan B, Yuan L, Huang $R$ and Chen G: Inhibition of pentose phosphate pathway suppresses acute myelogenous leukemia. Tumour Biol 37: 6027-6034, 2016

78. Lowman XH, McDonnell MA, Kosloske A, Odumade OA, Jenness C, Karim CB, Jemmerson R and Kelekar A: The proapoptotic function of Noxa in human leukemia cells is regulated by the kinase Cdk5 and by glucose. Mol Cell 40: 823-833, 2010.

79. Yamamoto T, Takano N, Ishiwata K, Ohmura M, Nagahata $Y$ Matsuura T, Kamata A, Sakamoto K, Nakanishi T, Kubo A, et al: Reduced methylation of PFKFB3 in cancer cells shunts glucose towards the pentose phosphate pathway. Nat Commun 5: 3480 , 2014.

80. Shan C, Elf S, Ji Q, Kang HB, Zhou L, Hitosugi T, Jin L, Lin R, Zhang L, Seo JH, et al: Lysine acetylation activates 6-phosphogluconate dehydrogenase to promote tumor growth. Mol Cell 55: $552-565,2014$.

81. Poulain L, Sujobert P, Zylbersztejn F, Barreau S, Stuani L, Lambert M, Palama TL, Chesnais V, Birsen R, Vergez F, et al: High mTORC1 activity drives glycolysis addiction and sensitivity to G6PD inhibition in acute myeloid leukemia cells Leukemia 31: 2326-2335, 2017

82. Hulleman E, Kazemier KM, Holleman A, VanderWeele DJ Rudin CM, Broekhuis MJ, Evans WE, Pieters R and Den Boer ML: Inhibition of glycolysis modulates prednisolone resistance in acute lymphoblastic leukemia cells. Blood 113: 2014-2021, 2009

83. Meynet O, Bénetéau M, Jacquin MA, Pradelli LA, Cornille A, Carles M and Ricci JE: Glycolysis inhibition targets Mcl-1 to restore sensitivity of lymphoma cells to ABT-737-induced apoptosis. Leukemia 26: 1145-1147, 2012.

84. Gregory MA, D'Alessandro A, Alvarez-Calderon F, Kim J, Nemkov T, Adane B, Rozhok AI, Kumar A, Kumar V, Pollyea DA, et al: ATM/G6PD-driven redox metabolism promotes FLT3 inhibitor resistance in acute myeloid leukemia. Proc Natl Acad Sci USA 113: E6669-E6678, 2016.

85. Gottschalk S, Anderson N, Hainz C, Eckhardt SG and Serkova NJ: Imatinib (STI571)-mediated changes in glucose metabolism in human leukemia BCR-ABL-positive cells. Clin Cancer Res 10: 6661-6668, 2004.

86. Karnauskas R, Niu Q, Talapatra S, Plas DR, Greene ME, Crispino JD and Rudin CM: $\mathrm{Bcl}-\mathrm{x}(\mathrm{L})$ and Akt cooperate to promote leukemogenesis in vivo. Oncogene 22: 688-698, 2003.

87. Ye H, Huang H, Cao F, Chen M, Zheng X and Zhan R: HSPB1 enhances SIRT2-mediated G6PD activation and promotes glioma cell proliferation. PLoS One 11: e0164285, 2016.

88. Tao L, Yu H, Liang R, Jia R, Wang J, Jiang K and Wang Z: Rev-erb $\alpha$ inhibits proliferation by reducing glycolytic flux and pentose phosphate pathway in human gastric cancer cells. Oncogenesis 8: 57, 2019.

89. Gu MJ, Huang QC, Bao CZ, Li YJ, Li XQ, Ye D, Ye ZH, Chen K and Wang JB: Attributable causes of colorectal cancer in China. BMC Cancer 18: 38, 2018.

90. Zhang Y, Chen Z and Li J: The current status of treatment for colorectal cancer in China: A systematic review. Medicine (Baltimore) 96: e8242, 2017.

91. Ishikawa M, Inoue T, Shirai T, Takamatsu K, Kunihiro S, Ishii $\mathrm{H}$ and Nishikata T: Simultaneous expression of cance stem Cell-like properties and Cancer-associated Fibroblast-like properties in a primary culture of breast cancer cells. Cancers (Basel) 6: 1570-1578, 2014

92. Tsouko E, Khan AS, White MA, Han JJ, Shi Y, Merchant FA, Sharpe MA, Xin L and Frigo DE: Regulation of the pentose phosphate pathway by an androgen Receptor-mTOR-mediated mechanism and its role in prostate cancer cell growth Oncogenesis 3: e103, 2014

93. Zampella EJ, Bradley EL Jr and Pretlow TG II: Glucose-6-phosphate dehydrogenase: A possible clinical indicator for prostatic carcinoma. Cancer 49: 384-387, 1982.

94. Pretlow TG II, Harris BE, Bradley EL Jr, Bueschen AJ, Lloyd KL and Pretlow TP: Enzyme activities in prostatic carcinoma related to Gleason grades. Cancer Res 45: 442-446, 1985.

95. Ros S, Santos CR, Moco S, Baenke F, Kelly G, Howell M, Zamboni $N$ and Schulze A: Functional metabolic screen identifies 6-phosphofructo-2-kinase/fructose-2,6-biphosphatase 4 as an important regulator of prostate cancer cell survival. Cancer Discov 2: 328-343, 2012.
96. Kaushik AK, Vareed SK, Basu S, Putluri V, Putluri N, Panzitt K, Brennan CA, Chinnaiyan AM, Vergara IA, Erho N, et al: Metabolomic profiling identifies biochemical pathways associated with Castration-resistant prostate cancer. J Proteome Res 13: 1088-1100, 2014.

97. Nna E, Tothill IE, Ludeman L and Bailey T: Endogenous control genes in prostate cells: Evaluation of gene expression using 'Real-Time' quantitative polymerase chain reaction. Med Princ Pract 19: 433-439, 2010.

98. Frederiks WM, Vizan P, Bosch KS, Vreeling-Sindelarova H, Boren $\mathbf{J}$ and Cascante $\mathrm{M}$ : Elevated activity of the oxidative and non-oxidative pentose phosphate pathway in (pre) neoplastic lesions in rat liver. Int J Exp Pathol 89: 232-240, 2008

99. Hu T, Zhang C, Tang Q, Su Y, Li B, Chen L, Zhang Z, Cai T and Zhu Y: Variant G6PD levels promote tumor cell proliferation or apoptosis via the STAT3/5 pathway in the human melanoma xenograft mouse model. BMC Cancer 13: 251, 2013.

100. Nobrega-Pereira S, Fernandez-Marcos PJ, Brioche T, Gomez-Cabrera MC, Salvador-Pascual A, Flores JM, Viña J and Serrano M: G6PD protects from oxidative damage and improves healthspan in mice. Nat Commun 7: 10894, 2016.

101. Hamanaka RB and Chandel NS: Mitochondrial reactive oxygen species regulate cellular signaling and dictate biological outcomes. Trends Biochem Sci 35: 505-513, 2010.

102. Maryanovich M and Gross A: A ROS rheostat for cell fate regulation. Trends Cell Biol 23: 129-134, 2013.

103. Weinberg F, Hamanaka R, Wheaton WW, Weinberg S, Joseph J, Lopez M, Kalyanaraman B, Mutlu GM, Budinger GR and Chandel NS: Mitochondrial metabolism and ROS generation are essential for Kras-mediated tumorigenicity. Proc Natl Acad Sci USA 107: 8788-8793, 2010.

104. Ying W: $\mathrm{NAD}^{+} / \mathrm{NADH}$ and $\mathrm{NADP}^{+} / \mathrm{NADPH}$ in cellular functions and cell death: Regulation and biological consequences. Antioxid Redox Signal 10: 179-206, 2008.

105. Peter B, Bogan KL and Charles B: NAD ${ }^{+}$metabolism in health and disease. Trends Biochem Sci 32: 12-19, 2007.

106. Berger F, Ramírez-Hernández MH and Ziegler M: The new life of a centenarian: Signalling functions of NAD(P). Trends Biochem Sci 29: 111-118, 2004.

107. Pollak N, Dölle C and Ziegler M: The power to reduce: Pyridine nucleotides-small molecules with a multitude of functions. Biochem J 402: 205-218, 2007

108. Rastogi R, Geng X, Li F and Ding Y: NOX Activation by subunit interaction and underlying mechanisms in disease. Front Cel Neurosci 10: 301, 2017

109. Meitzler JL, Antony S, Wu Y, Juhasz A, Liu H, Jiang G, Lu J, Roy K and Doroshow JH: NADPH Oxidases: A perspective on reactive oxygen species production in tumor biology. Antioxid Redox Signal 20: 2873-2889, 2014.

110. Prasad S, Gupta SC and Tyagi AK: Reactive oxygen species (ROS) and cancer: Role of antioxidative nutraceuticals. Cancer Lett 387: 95-105, 2017.

111. Bedard K and Krause KH: The NOX family of ROS-generating NADPH oxidases: Physiology and pathophysiology. Physiol Rev 87: 245-313, 2007.

112. Mittler R: ROS are good. Trends Plant Sci 22: 11-19, 2017.

113. de Atauri P, Benito A, Vizán P, Zanuy M, Mangues R, Marín S and Cascante M: Carbon metabolism and the sign of control coefficients in metabolic adaptations underlying K-ras transformation. Biochim Biophys Acta 1807: 746-754, 2011.

114. Jiang P, Du W, Wang X, Mancuso A, Gao X, Wu M and Yang X: p53 regulates biosynthesis through direct inactivation of glucose-6-phosphate dehydrogenase. Nat Cell Biol 13: 310-316, 2011.

115. Fujita M, Imadome K, Endo S, Shoji Y, Yamada S and Imai T: Nitric oxide increases the invasion of pancreatic cancer cells via activation of the PI3K-AKT and RhoA pathways after carbon ion irradiation. FEBS Lett 588: 3240-3250, 2014.

116. Li W, Cao L, Han L, Xu Q and Ma Q: Superoxide dismutase promotes the epithelial-mesenchymal transition of pancreatic cancer cells via activation of the $\mathrm{H} 2 \mathrm{O} 2 / \mathrm{ERK} / \mathrm{NF}-\mathrm{NF}-\kappa \mathrm{B}$ axis. Int J Oncol 46: 2613-2620, 2015

117. Kong DH, Li S, Du ZX, Liu C, Liu BQ, Li C, Zong ZH and Wang HQ: BAG3 elevation inhibits cell proliferation via direct interaction with G6PD in hepatocellular carcinomas. Oncotarget 7: 700-711, 2016.

118. Rosati A, Graziano V, De Laurenzi V, Pascale M and Turco MC: BAG3: A multifaceted protein that regulates major cell pathways. Cell Death Dis 2: e141, 2011. 
119. Behl C: BAG3 and friends: Co-chaperones in selective autophagy during aging and disease. Autophagy 7: 795-798, 2011.

120. Cai T, Kuang Y, Zhang C, Zhang Z, Chen L, Li B, Li Y, Wang Y, Yang H, Han Q and Zhu Y: Glucose-6-phosphate dehydrogenase and NADPH oxidase 4 control STAT3 activity in melanoma cells through a pathway involving reactive oxygen species, c-SRC and SHP2. Am J Cancer Res 5: 1610-1620, 2015.

121. Hedberg Y, Ljungberg B, Roos G and Landberg G: Expression of cyclin D1, D3, E, and p27 in human renal cell carcinoma analysed by tissue microarray. Br J Cancer 88: 1417-1423, 2003.

122. Sun X, Liu B, Wang J, Li J and Ji WY: Inhibition of p21-activated kinase 4 expression suppresses the proliferation of Hep-2 laryngeal carcinoma cells via activation of the ATM/Chk1/2/ p53 pathway. Int J Oncol 42: 683-689, 2013.

123. Zhang X, Zhang X, Li Y, Shao Y, Xiao J, Zhu G and Li F: PAK4 regulates G6PD activity by $\mathrm{p} 53$ degradation involving colon cancer cell growth. Cell Death Dis 8: e2820, 2017.

124. Ma X, Wang L, Huang D, Li Y, Yang D, Li T, Li F, Sun L, Wei H, $\mathrm{He} \mathrm{K}$, et al: Polo-like kinase 1 coordinates biosynthesis during cell cycle progression by directly activating pentose phosphate pathway. Nat Commun 8: 1506, 2017.

125. Gu Y, Mi W, Ge Y, Liu H, Fan Q, Han C, Yang J, Han F, Lu X and $\mathrm{Yu} \mathrm{W:} \mathrm{GlcNAcylation} \mathrm{plays} \mathrm{an} \mathrm{essential} \mathrm{role} \mathrm{in} \mathrm{breast} \mathrm{cancer}$ metastasis. Cancer Res 70: 6344-6351, 2010.

126. Mi W, Gu Y, Han C, Liu H, Fan Q, Zhang X, Cong Q and Yu W: $\mathrm{O}-$ GlcNAcylation is a novel regulator of lung and colon cancer malignancy. Biochim Biophys Acta 1812: 514-519, 2011.

127. Tokuda K, Baron B, Yamashiro C, Kuramitsu Y, Kitagawa T, Kobayashi M, Sonoda KH and Kimura K: Up-regulation of the pentose phosphate pathway and HIF-1 $\alpha$ expression during neural progenitor cell induction following glutamate treatment in rat ex vivo retina. Cell Biol Int 44: 137-144, 2020.
128. Reina-Campos M, Moscat J and Diaz-Meco M: Metabolism shapes the tumor microenvironment. Curr Opin Cell Biol 48: 47-53, 2017.

129. Singh L, Aldosary S, Saeedan AS, Ansari MN and Kaithwas G: Prolyl hydroxylase 2: A promising target to inhibit hypoxia-induced cellular metabolism in cancer cells. Drug Discov Today 23: 1873-1882, 2018.

130. Hanahan D and Weinberg RA: Hallmarks of cancer: The next generation. Cell 144: 646-674, 2011.

131. Cabrales P: RRx-001 acts as a dual small molecule checkpoint inhibitor by downregulating CD47 on cancer cells and SIRP- $\alpha$ on Monocytes/Macrophages. Transl Oncol 12: 626-632, 2019.

132. Yalcin O, Oronsky B, Carvalho LJ, Kuypers FA, Scicinski J and Cabrales P: From METS to malaria: RRx-001, a multi-faceted anticancer agent with activity in cerebral malaria. Malar J 14: $218,2015$.

133. Das DS, Ray A, Das A, Song Y, Tian Z, Oronsky B, Richardson P, Scicinski J, Chauhan D and Anderson KC: A novel hypoxia-selective epigenetic agent RRx-001 triggers apoptosis and overcomes drug resistance in multiple myeloma cells. Leukemia 30: 2187-2197, 2016.

134. Mele L, Paino F, Papaccio F, Regad T, Boocock D, Stiuso P, Lombardi A, Liccardo D, Aquino G, Barbieri A, et al: A new inhibitor of glucose-6-phosphate dehydrogenase blocks pentose phosphate pathway and suppresses malignant proliferation and metastasis in vivo. Cell Death Dis 9: 572, 2018. 